\title{
Effects of Oakmoss and Its Components on Biofilm Formation of Legionella pneumophila
}

\author{
Harue Nomura, ${ }^{* a}$ Yasunori Isshiki, ${ }^{a}$ Keisuke Sakuda, ${ }^{b}$ Katsuya Sakuma, ${ }^{b}$ and Seiichi Kondo ${ }^{a}$ \\ ${ }^{a}$ Department of Microbiology, School of Pharmaceutical Sciences, Josai University; Sakado, Saitama 350-0295, \\ Japan: and ${ }^{b}$ Fragrance R\&D Department, Ogawa \& Co., Ltd.; 15-7 Chidori, Urayasu, Chiba 279-0032, Japan. \\ Received December 6, 2012; accepted February 14, 2013
}

\begin{abstract}
Oakmoss and its components are known as antibacterial agents, specifically against Legionella pneumophila. In the present study, we investigated the effects of oakmoss and its components (phenol, didepside and isochromen derivatives) on $L$. pneumophila biofilm formation, with particular reference to the bactericidal activity (minimum bactericidal concentration; MBC) of these components against the bacterial cells in the biofilm. Of the 20 compounds tested, two didepside derivatives and four phenol derivatives reduced biofilm formation by more than $\mathbf{5 0 \%}$ of that observed for the control at their respective minimum inhibitory concentrations $(1 / 2 \times M I C)$. The inhibitory activities of these compounds were either equivalent to or greater than that of the clarithromycin reference. Isochromen derivatives had no effect on biofilm formation. Analysis of bactericidal activity of didepside and isochromen derivatives revealed that three of four didepside derivatives and one of four isochromen derivatives exhibited high bactericidal activity (MBC: $32.0-74.7 \mu \mathrm{g} / \mathrm{mL}$ ) against the $L$. pneumophila in the biofilm after $24 \mathrm{~h}$ or $48 \mathrm{~h}$ of co-incubation; the antibacterial activities of these compounds were almost equivalent to clarithromycin and chlorhexidine gluconate (MBC: 42.7-64.0 $\mu \mathrm{g}$ / $\mathrm{mL}$ ) that were used as references. Thus, based on their anti-biofilm forming and bactericidal activities, didepside derivatives are considered to be good candidates for disinfectants against L. pneumophila.
\end{abstract}

Key words oakmoss; antibacterial activity; bactericidal activity; Legionella pneumophila; biofilm formation

Legionellosis is a severe form of pneumonia or non-pneumonic Pontiac fever caused by Gram-negative bacteria belonging to the genus Legionella, which are widely distributed in natural water environments and artificial water supply systems. In addition to being the type species of this genus, Legionella pneumophila is the main causative agent of legionellosis. Inhalation of L. pneumophila-contaminated water can lead to an outbreak of legionellosis. In the natural environment, $L$. pneumophila exists as free-living plankton, as intracellular parasites of protozoans such as Acanthamoeba spp., ${ }^{1)}$ and in mixed-community biofilms. $^{2-5)}$ Biofilms are assemblages of bacteria that occur in extracellular polymeric matrices on biotic or abiotic surfaces. Biofilms confer numerous advantages to bacteria, particularly for resistance to antibacterial agents. ${ }^{6,7)}$ In the case of $L$. pneumophila, biofilms confer resistance to stressful environmental conditions and to the actions of biocides, such as antibiotics and disinfectants. ${ }^{8-10)}$

Biofilms can form in artificial water supply systems, such as air conditioning systems, fountains, public baths and spas. It is therefore extremely important to keep the water that is supplied through such artificial water systems free from this bacterial species to avoid outbreaks of legionellosis. Consequently, developing new antibacterial agents and disinfectants that are effective against, not only L. pneumophila, but also biofilms containing this bacterium is considered very important.

Oakmoss is a natural fragrance ingredient derived from the lichen, Evernia prunastri (L.) ARCH., which grows throughout central and southern Europe. The antibacterial characteristics of oakmoss and its components have been reported by us previously. ${ }^{11,12)}$ Specifically, we demonstrated that oakmoss and its components exhibited antibacterial activities against members of the genus Legionella, including clinical and en-

The authors declare no conflict of interest. vironmental isolates of L. pneumophila and other Legionella spp. ${ }^{12)}$ In the present study, we investigated the effect of oakmoss and its components on L. pneumophila biofilm formation and the bactericidal activity of oakmoss against the bacterium in biofilms. One of the aims of the study was to develop a novel disinfectant preventing L. pneumophila infection. Since clarithromycin, chlorhexidine gluconate and cinnamic aldehyde are all known to inhibit biofilm formation by a variety of bacterial species, we used these compounds as references.

\section{MATERIALS AND METHODS}

Bacterial Strain, Fragrance Ingredients and Antibiotics Legionella pneumophila Philadelphia 1 strain JCM7571 was used to examine anti-biofilm formation and bactericidal activities.

Absolute Mousse De Chene Selecta (OM, Charabot, Grasse, France), Oakmoss Absolute AT 086 (OMAT, H. Reynaud \& Fils, Monterun Les Bains, France) and cinnamic aldehyde (CA) were provided by Ogawa \& Co., Ltd. (Chiba, Japan) and stored at $4^{\circ} \mathrm{C}$ until use. Clarithromycin (CAM) and chlorhexidine gluconate $(\mathrm{CHG})$ (Wako Pure Chemical Ind., Ltd., Osaka, Japan) were used as reference compounds. The following compounds which have been isolated from OM and OMAT as previously reported ${ }^{12)}$ were used; 5-methylbenzene-1,3-diol (1), 3-methoxy-5-methylphenol (2), 2,6-dihydroxy-4-methylbenzaldehyde (3), methyl 2,4-dihydroxy-6-methylbenzoate (4), 3-hydroxy-5-methylphenyl 2,4-dihydroxy-6-methylbenzoate (5), ethyl 2,4-dihydroxy6-methylbenzoate (6), methyl 2,4-dihydroxy-3,6-dimethylbenzoate (7), isopropyl 2,4-dihydroxy-6-methylbenzoate (8), 3-methoxy-5-methylphenyl 2,4-dihydroxy-6-methylbenzoate (9), 3-hydroxy-5-methylphenyl 2-hydroxy-4-methoxy6-methylbenzoate (10), ethyl 2-hydroxy-4-methoxy-6-methylbenzoate (11), 6,8-dihydroxy-3-pentyl-1H-isochromen-1-one 


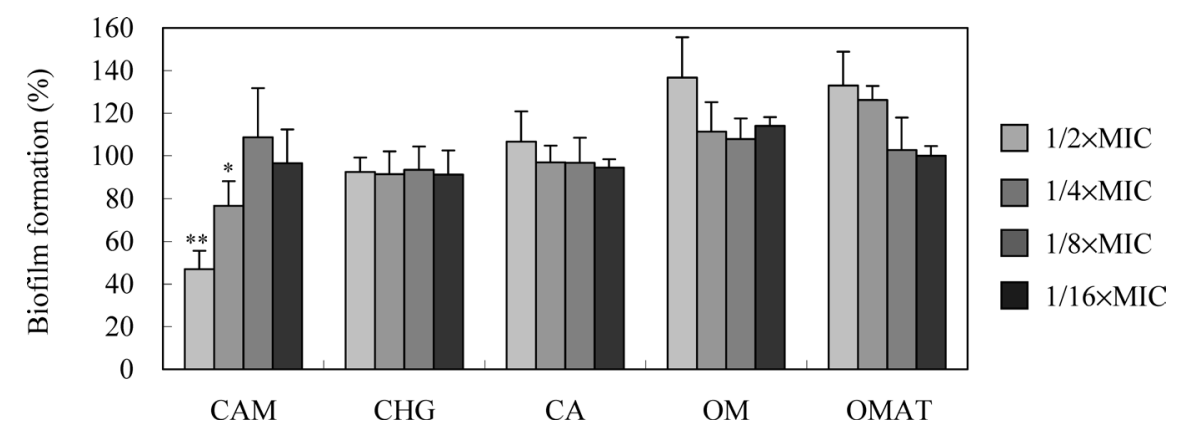

Fig. 1. Effects of CAM, CHG, CA, OM and OMAT on L. pneumophila Biofilm Formation $(* * p<0.01, * p<0.05)$

The MIC values were CAM; $0.042 \mu \mathrm{g} / \mathrm{mL}, \mathrm{CHG} ; 0.8 \mu \mathrm{g} / \mathrm{mL}, \mathrm{CA} ; 48.0 \mu \mathrm{g} / \mathrm{mL}, \mathrm{OM} ; 10.7 \mu \mathrm{g} / \mathrm{mL}, \mathrm{OMAT} ; 10.7 \mu \mathrm{g} / \mathrm{mL}$.

(12), ethyl 3-formyl-2,4-dihydroxy-6-methylbenzoate (13), 8-(2,4-dihydroxy-6-pentylphenoxy)-6-hydroxy-3-pentyl-1 $H$ isochromen-1-one (14), isopropyl 3-formyl-2,4-dihydroxy6-methylbenzoate (15), 3-methoxy-5-methylphenyl 2-hydroxy4-methoxy-6-methylbenzoate (16), 8-(2-hydroxy-4-methoxy-6pentylphenoxy)-6-hydroxy-3-pentyl- $1 H$-isochromen-1-one (17), 2,5-dimethylbenzene-1,3-diol (18), 3-chloro-2,6-dihydroxy4-methylbenzaldehyde (19), 8-(2,4-dihydroxy-6-(2-oxoheptyl)phenoxy)-6-hydroxy-3-pentyl-1H-isochromen-1-one (20).

Biofilm Formation Assay A $72 \mathrm{~h}$ culture of $L$. pneumophila JCM7571 containing approximately $10^{9}$ colony forming units $(\mathrm{CFU}) / \mathrm{mL}$ was diluted to $2.0 \times 10^{3} \mathrm{CFU} / \mathrm{mL}$ with a buffered yeast extract broth supplemented with $0.1 \%$ $\alpha$-ketoglutarate (BYE- $\alpha$; Becton Dickinson, Sparks, MD, U.S.A.) containing $1 \%$ yeast extract, $1 \% \quad N$-(2-acetamide)2-aminoethanesulfonic acid, $0.025 \%$ iron(II) diphosphate, $0.1 \%$ potassium $\alpha$-ketoglutarate and $1 \%$ L-cysteine. The diluted culture $(50 \mu \mathrm{L})$ was mixed with $50 \mu \mathrm{L}$ of sample solutions in a flat-bottomed, 96-well polystyrene tissue-culture plate (Sumitomo Bakelite Co., Ltd., Tokyo, Japan). The final concentrations of the samples were $1 / 2,1 / 4,1 / 8$ and $1 / 16 \times$ minimum inhibitory concentration (MIC) and the test medium contained $0.5 \%$ dimethyl sulfoxide (DMSO). After incubation at $37^{\circ} \mathrm{C}$ for $96 \mathrm{~h}$ in a wet-box, the medium solution was removed and the plates were washed with BYE- $\alpha$. The remaining biofilm, which was formed during incubation, was stained with $100 \mu \mathrm{L}$ of $0.1 \%$ crystal violet solution at room temperature for $15 \mathrm{~min}$. After removal of the crystal violet solution and washing the biofilm three times with distilled water, the stained biofilm was dissolved in $200 \mu \mathrm{L}$ of $33 \%$ acetic acid. Then, $125 \mu \mathrm{L}$ of the solution was transferred into another flat-bottomed, 96-well polystyrene tissue-culture plate and the absorbancy at $570 \mathrm{~nm}\left(A_{570 \mathrm{~nm}}\right)$ was measured using a microplate reader (Model 550; Bio-Rad Laboratories, CA, U.S.A.). The biofilmforming positive and negative controls (blank) did not contain samples and bacteria, respectively. The percentage biofilm formation was calculated using the following equation:

$$
\begin{aligned}
& \text { biofilm formation (\%) } \\
& =\frac{A_{570 \mathrm{~nm}} \text { of sample-treatment wells }-A_{570 \mathrm{~nm}} \text { of blank }}{A_{570 \mathrm{~nm}} \text { of } 0.5 \% \text { DMSO-treatment wells }-A_{570 \mathrm{~nm}} \text { of blank }} \\
& \quad \times 100
\end{aligned}
$$

For each assay, biofilm formation was estimated using 6 replicate samples containing samples at the same concentrations. Biofilm formation was analyzed using Student's $t$-test and data were presented as the mean \pm standard deviation of three separate observations.
Determination of Minimum Bactericidal Concentrations (MBCs) The $72 \mathrm{~h}$ bacterial culture was diluted to $1.0 \times 10^{3} \mathrm{CFU} / \mathrm{mL}$ with BYE- $\alpha$. One hundred microliters of the bacterial suspension was dispensed into a flat-bottomed, 96-well polystyrene tissue-culture plate and incubated at $37^{\circ} \mathrm{C}$ for $96 \mathrm{~h}$ in a wet-box. Wells containing biofilm were gently washed with $200 \mu \mathrm{L}$ of BYE- $\alpha$ solution to remove the planktonic bacterial cells. Serially diluted solutions $(100 \mu \mathrm{L})$ of antibacterial agents ranging from $256.0 \mu \mathrm{g} / \mathrm{mL}$ to their respective MICs were added to each well and the plate was incubated at $37^{\circ} \mathrm{C}$ for $1 \mathrm{~h}, 24 \mathrm{~h}$ and $48 \mathrm{~h}$. After removing the solutions of antibacterial agents, the wells were washed with BYE- $\alpha$ and the bacterial cells in the biofilm were washed form the wells by vigorous shaking with $100 \mu \mathrm{L}$ of phosphate buffered saline (PBS). MBCs were taken as the lowest concentration at which the samples showed no visible colony formation on a buffered charcoal yeast extract agar supplemented with $0.1 \%$ $\alpha$-ketoglutarate (BCYE- $\alpha$, Becton Dickinson) subculture.

\section{RESULTS}

L. pneumophila Biofilm Formation We previously reported the antibacterial activities of oakmoss and its components against L. pneumophila JCM7571. ${ }^{12)}$ The oakmoss and its components all exhibited antibacterial activity, with MICs ranging $0.8-213.3 \mu \mathrm{g} / \mathrm{mL}$. In the present study, the effects of these compounds on L. pneumophila JCM7571 biofilm formation were examined at concentrations of $1 / 2-1 / 16 \times \mathrm{MIC}$. The effects of CAM, CHG, CA, OM and OMAT on biofilm formation are shown in Fig. 1. At a concentration of $1 / 2 \times \mathrm{MIC}$, CAM reduced the biofilm formation by $47.0 \pm 8.5 \%$ compared with positive control. $\mathrm{CHG}$ and $\mathrm{CA}$ did not affect biofilm formation at the concentration tested. At a concentration of $1 / 2 \times \mathrm{MIC}, \mathrm{OM}$ and OMAT enhanced biofilm formation by $136.8 \pm 18.9 \%$ and $132.9 \pm 15.9 \%$, respectively, compared to a positive control.

Didepside derivatives (compounds 9, 10, 16) inhibited biofilm formation in a dose-dependent manner (Fig. 2). In particular, at a concentration of $1 / 2 \times \mathrm{MIC}$, compounds 9 and 16 reduced biofilm formation by $23.6 \pm 8.7 \%$ and $17.8 \pm 2.1 \%$, respectively, compared to a positive control; the magnitude of this reduction was higher than that observed using CAM at the same concentration. However, compound 5, which is structurally closely related to compounds 9 and 16, did not show any effect on the biofilm formation. Similarly, as shown in Fig. 3, all isochromen derivatives were inactive against the biofilm formation. 


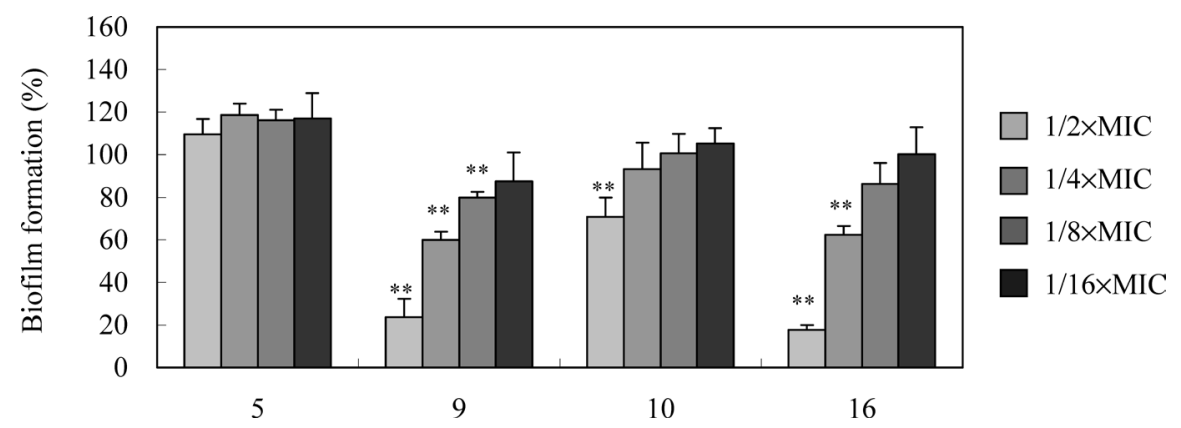

Fig. 2. Effects of Didepside Derivatives on L. pneumophila Biofilm Formation $(* * p<0.01)$

The MIC values were compound $\mathbf{5} ; 8.0 \mu \mathrm{g} / \mathrm{mL}$, compound $\mathbf{9} ; 8.0 \mu \mathrm{g} / \mathrm{mL}$, compound $\mathbf{1 0} ; 4.0 \mu \mathrm{g} / \mathrm{mL}$ and compound $\mathbf{1 6} ; 8.0 \mu \mathrm{g} / \mathrm{mL}$.

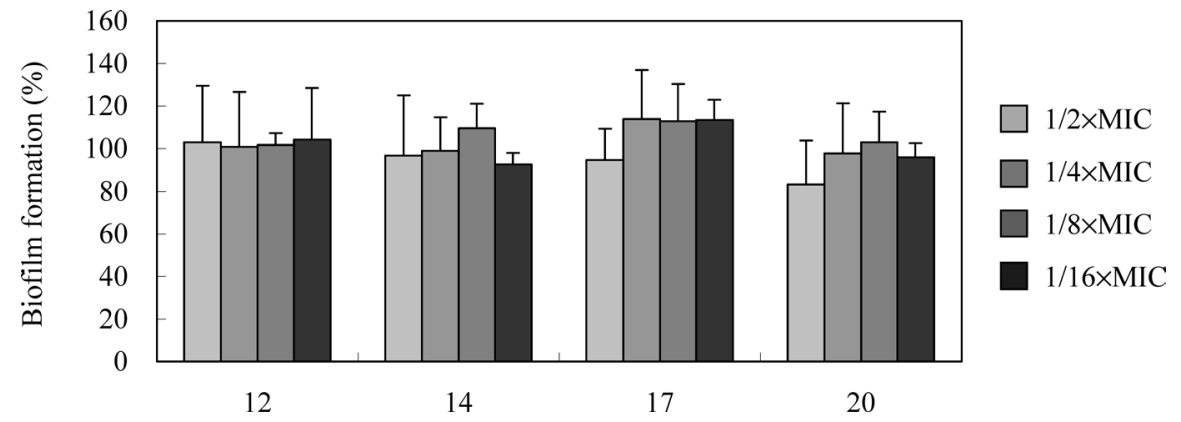

Fig. 3. Effects of Isochromen Derivatives on L. pneumophila Biofilm Formation

The MIC values were compound 12; $1.7 \mu \mathrm{g} / \mathrm{mL}$, compound $14 ; 2.0 \mu \mathrm{g} / \mathrm{mL}$, compound $17 ; 6.7 \mu \mathrm{g} / \mathrm{mL}$ and compound 20;8.0 $\mu \mathrm{g} / \mathrm{mL}$.

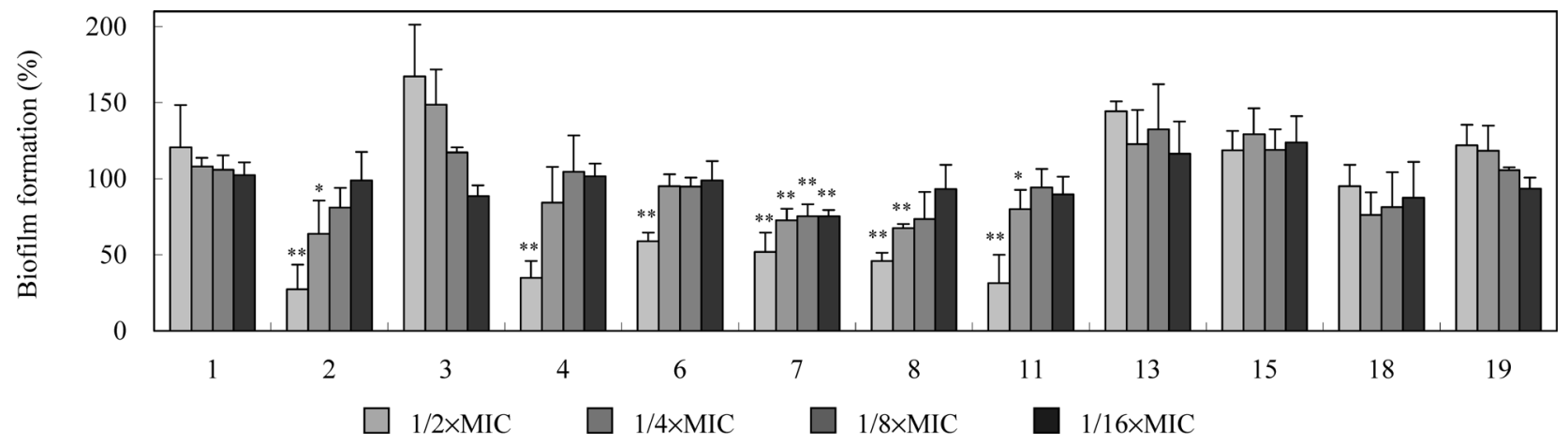

Fig. 4. Effects of Phenol Derivatives on L. pneumophila Biofilm Formation ( ${ }^{*} p<0.01,{ }^{*} p<0.05$ )

The MIC values were compound $\mathbf{1} ; 213.3 \mu \mathrm{g} / \mathrm{mL}$, compound $2 ; 213.3 \mu \mathrm{g} / \mathrm{mL}$, compound $3 ; 128.0 \mu \mathrm{g} / \mathrm{mL}$, compound $4 ; 106.7 \mu \mathrm{g} / \mathrm{mL}$, compound $\mathbf{6} ; 32.0 \mu \mathrm{g} / \mathrm{mL}$, compound 7; $21.3 \mu \mathrm{g} / \mathrm{mL}$, compound $8 ; 26.7 \mu \mathrm{g} / \mathrm{mL}$, compound $11 ; 106.7 \mu \mathrm{g} / \mathrm{mL}$, compound 13;16.0 $\mu \mathrm{g} / \mathrm{mL}$, compound 15;8.0 $\mu \mathrm{g} / \mathrm{mL}$, compound 18;74.4 $\mu \mathrm{g} / \mathrm{mL}$ and compound 19; $32.0 \mu \mathrm{g} / \mathrm{mL}$.

Several phenol derivatives decreased biofilm formation. Compounds 2, 4, 6, 7, 8 and 11 reduced the biofilm formation in a dose-dependent manner (Fig. 4). Of these, compounds 2, 4, 8 and 11 markedly decreased biofilm formation $(27.2 \pm$ $16.3 \%, 34.9 \pm 11.1 \%, 45.9 \pm 5.4 \%$ and $31.3 \pm 18.6 \%$ compared to the positive control, respectively) at a concentration of $1 / 2 \times$ MIC. Conversely, at a concentration of $1 / 2 \times$ MIC, compounds 3, 13, 15 and 19 enhanced biofilm formation by $167.4 \pm 34.0 \%-144.3 \pm 6.6 \%$ compared to a positive control.

Bactericidal Activity against $L$. pneumophila in Biofilms The bactericidal activity of oakmoss and its components was examined by estimating the MBCs against $L$. pneumophila JCM7571 cells in the biofilm. In this experiment, oakmoss and eight of its components were selected, i.e., four didepside derivatives (compounds $\mathbf{5}, \mathbf{9}, \mathbf{1 0}, \mathbf{1 6}$ ) and four isochromen derivatives (compounds 12, 14, 17, 20). All of these compounds were previously reported to exhibit highly antibacterial activity against $L$. pneumophila JCM7571, with MICs and MBCs ranging from 1.7 to $8.0 \mu \mathrm{g} / \mathrm{mL}$ and 3.0 to $32.0 \mu \mathrm{g} / \mathrm{mL}$, respectively. ${ }^{12)}$ After $1 \mathrm{~h}$ of co-incubation with the biofilm, all of the compounds tested showed no or very little bactericidal activity (Table 1). However, when the co-incubation times were extended to 24 and $48 \mathrm{~h}$, three of the didepside derivatives (compounds $5,9,10$ ) and one of the isochromen derivatives (compound 12) showed bactericidal activities with MBCs ranging from 32.0 to $74.7 \mu \mathrm{g} / \mathrm{mL}$, which were equivalent to those of $\mathrm{CHG}$ and CAM. The MBC values of these compounds at $24 \mathrm{~h}$ and $48 \mathrm{~h}$ did not change markedly. Although CA is known to exhibit antibacterial activity toward planktonic cells of L. pneumophila ${ }^{12)}$ it did not show any bactericidal activity against the bacterial cells in the biofilm. 
Table 1. Minimum Bactericidal Concentrations (MBCs) of Oakmoss and Its Components against L. pneumophila in Biofilm

\begin{tabular}{lccr}
\hline \hline & \multicolumn{3}{c}{ MBC $(\mu \mathrm{g} / \mathrm{mL})$} \\
\cline { 2 - 4 } & $1 \mathrm{~h}$ & $24 \mathrm{~h}$ & $48 \mathrm{~h}$ \\
\hline OM & $>256.0$ & $>256.0$ & $\geq 256.0$ \\
OMAT & $>256.0$ & $>256.0$ & $\geq 256.0$ \\
Didepside derivatives & & \\
$\mathbf{5}$ & 256.0 & 74.7 & 64.0 \\
$\mathbf{9}$ & 256.0 & 58.7 & 37.3 \\
$\mathbf{1 0}$ & 213.3 & 32.0 & 32.0 \\
$\mathbf{1 6}$ & $>256.0$ & $>256.0$ & $>256.0$ \\
Isochromen derivatives & & \\
$\mathbf{1 2}$ & $\geq 256.0$ & 53.3 & 42.7 \\
$\mathbf{1 4}$ & $>256.0$ & $\geq 256.0$ & 256.0 \\
$\mathbf{1 7}$ & $>256.0$ & $>256.0$ & $>256.0$ \\
$\mathbf{2 0}$ & $>256.0$ & $\geq 256.0$ & 213.3 \\
\hline $\mathrm{CHG}^{a)}$ & $>256.0$ & 58.7 & 42.7 \\
$\mathrm{CAM}^{b)}$ & $>256.0$ & 64.0 & 42.7 \\
$\mathrm{CA}^{c)}$ & $>256.0$ & $>256.0$ & 234.7 \\
\hline
\end{tabular}

Values are means obtained from three independent duplicated experiments. a) Chlorhexidine gluconate. $b$ ) Clarithromycin. c) Cinnamic aldehyde.

\section{DISCUSSION}

The inhibitory effects of CAM, CHG and CA on biofilm formation and against several bacterial species have been reported previously; CAM: Mycobacterium avium ${ }^{13)}$ and Pseudomonas aeruginosa, ${ }^{14)}$ CHG: Escherichia coli, Klebsiella pneumonia and P. aeruginosa ${ }^{15)}$ CA: Staphylococcus epidermidis and Cronobacter sakazakii. ${ }^{16-18)}$ In the present study, CAM inhibited L. pneumophila biofilm formation at a concentration of $1 / 2 \times \mathrm{MIC}$, but $\mathrm{CHG}$ and $\mathrm{CA}$ did not inhibit biofilm formation by this bacterium at subMIC concentrations. It has been proposed that CAM degrades the membranous structure of biofilm or suppresses the production of biofilm matrices, ${ }^{19,20)}$ and it is suggested here that CAM affects the formation of L. pneumophila biofilm in the same manner. The oakmoss (OM or OMAT) itself enhanced the biofilm formation of L. pneumophila. Although the oakmoss contain several compounds which enhance the biofilm formation (Fig. 4), their contents in the oakmoss are very low. ${ }^{12)}$ It is therefore inconceivable that these compounds contribute to the enhancement of the biofilm formation. On the other hand, the oakmoss contains large amount of high-molecular weight unknown materials. ${ }^{12)}$ These unknown material(s) might promote the cell adhesion, that is the initial stage of biofilm formation, to surfaces as reported by Ofek et al. ${ }^{21)}$ and Sandasi et al..$^{22)}$

Several mechanisms of anti-biofilm forming activity of essential oils have been described, e.g., damaging of the microbial membrane, ${ }^{18,23)}$ inhibition of swimming motility ${ }^{18)}$ and cell adhesion, ${ }^{21)}$ and binding to LasR causing inhibition of LasR dependent biofilm formation, swimming and motility of $P$. aeruginosa. ${ }^{24)}$ In the present study, we demonstrated that two of the four didepside derivatives reduced biofilm formation by more than $50 \%$ compared with the control. These four didepside derivatives are structurally closely related; they carry hydroxy or methoxy groups as substituent groups on their common structure. The differences in the effects of these compounds on biofilm formation or on the biofilm itself could be due to their physicochemical properties, however the mechanism of anti-biofilm forming activity of these components against $L$. pneumophila is currently unclear.

In the analysis examining the effect of selected oakmoss components against L. pneumophila cells in the biofilms themselves, three of four didepside derivatives and one of four isochromen derivatives exhibited bactericidal activity comparable to that of CAM and CHG. However, the MBCs of compounds 5, 9 and 10 were $4-7$ fold higher than the MBCs against planktonic cells of $L$. pneumophila. The didepside derivative compound $\mathbf{1 6}$ was markedly more hydrophobic than the other didepside derivatives and may explain why compound $\mathbf{1 6}$ did not show bactericidal activity against bacterial cells in hydrophilic biofilm matrices. Indeed, the same may be true for those isochromen derivatives that did not exhibit any bactericidal activity. Compounds 14, 17 and 20 have a 6-pentylphenoxy group at the C-8 position of 6-hydroxy3 -pentyl-1H-isochromen-1-one, which is the basic structure of isochromen. Compared with compound 12, these compounds are much more hydrophobic and did not show any bactericidal activity against bacterial cells in the biofilm. The MBC value for $\mathrm{CHG}$, a widely used disinfectant, was approximately 70 -fold higher than that observed against planktonic cells. It is possible that the hydrophilic biofilm matrices of $L$. pneumophila act as a protective barrier and that biofilm formation in L. pneumophila may increase the resistance of bacteria to antibacterial agents.

The oakmoss itself exhibits high antibacterial activity against planktonic cells of $L$. pneumophila but it does not show any antibacterial activity against $L$. pneumophila cells in the biofilm. In addition, the oakmoss enhances the biofilm formation. Isochromen derivatives also show markedly high antibacterial activity against planktonic cells of $L$. pneumophila but not (except for 12) against L. pneumophila cells in the biofilm and they do not effect on the biofilm formation. Thus, didepside derivatives, in particular compounds 9 and 16, are considered to be good candidates for disinfectants against $L$. pneumophila based on their anti-biofilm forming activity and bactericidal activity against both planktonic cells and cells in the biofilm.

\section{REFERENCES}

1) Atlas RM. Legionella: from environmental habitats to disease pathology, detection and control. Environ. Microbiol., 1, 283-293 (1999).

2) Rogers J, Dowsett AB, Dennis PJ, Lee JV, Keevil CW. Influence of temperature and plumbing material selection on biofilm formation and growth of Legionella pneumophila in a model potable water system containing complex microbial flora. Appl. Environ. Microbiol., 60, 1585-1592 (1994).

3) Walker JT, Bradshaw DJ, Bennett AM, Fulford MR, Martin MV, Marsh PD. Microbial biofilm formation and contamination of dental-unit water systems in general dental practice. Appl. Environ. Microbiol., 66, 3363-3367 (2000).

4) Declerck P. Biofilms: the environmental playground of Legionella pneumophila. Environ. Microbiol., 12, 557-566 (2010).

5) Pécastaings S, Bergé M, Dubourg KM, Roques C. Sessile Legionella pneumophila is able to grow on surfaces and generate structured monospecies biofilms. Biofouling, 26, 809-819 (2010).

6) Stewart PS, Costerton JW. Antibiotic resistance of bacteria in biofilms. Lancet, 358, 135-138 (2001).

7) Mah TF, O'Toole GA. Mechanisms of biofilm resistance to anti- 
microbial agents. Trends Microbiol., 9, 34-39 (2001).

8) Cooper IR, Hanlon GW. Resistance of Legionella pneumophila serotype 1 biofilms to chlorine-based disinfection. J. Hosp. Infect., 74, 152-159 (2010).

9) Kim BR, Anderson JE, Mueller SA, Gaines WA, Kendall AM. Literature review-Efficacy of various disinfectants against Legionella in water systems. Water Res., 36, 4433-4444 (2002).

10) Wright JB, Ruseska I, Costerton JW. Decreased biocide susceptibility of adherent Legionella pneumophila. J. Appl. Bacteriol., 71, 531-538 (1991).

11) Shimizu I, Isshiki Y, Nomura H, Sakuda K, Sakuma K, Kondo S. The antibacterial activity of fragrance ingredients against Legionella pneumophila. Biol. Pharm. Bull., 32, 1114-1117 (2009).

12) Nomura H, Isshiki Y, Sakuda K, Sakuma K, Kondo S. The antibacterial activity of compounds isolated from oakmoss against Legionella pneumophila and other Legionella spp. Biol. Pharm. Bull., 35, 1560-1567 (2012).

13) Carter G, Young LS, Bermudez LE. A subinhibitory concentration of clarithromycin inhibits Mycobacterium avium biofilm formation. Antimicrob. Agents Chemother., 48, 4907-4910 (2004).

14) Wozniak DJ, Keyser R. Effects of subinhibitory concentrations of macrolide antibiotics on Pseudomonas aeruginosa. Chest, 125 (Suppl.), 62S-69S, quiz, 69S (2004).

15) Houari A, Di Martino P. Effect of chlorhexidine and benzalkonium chloride on bacterial biofilm formation. Lett. Appl. Microbiol., 45, 652-656 (2007).

16) Nuryastuti T, van der Mei HC, Busscher HJ, Iravati S, Aman AT, Krom BP. Effect of cinnamon oil on icaA expression and biofilm formation by Staphylococcus epidermidis. Appl. Environ. Microbiol., 75, 6850-6855 (2009).

17) Amalaradjou MAR, Venkitanarayanan K. Effect of trans-cinnamaldehyde on inhibition and inactivation of Cronobacter sakazakii biofilm on abiotic surfaces. J. Food Prot., 74, 200-208 (2011).

18) Niu C, Gilbert ES. Colorimetric method for identifying plant essential oil components that affect biofilm formation and structure. Appl. Environ. Microbiol., 70, 6951-6956 (2004).

19) Yasuda H, Ajiki Y, Koga T, Kawada H, Yokota T. Interaction between biofilms formed by Pseudomonas aeruginosa and clarithromycin. Antimicrob. Agents Chemother., 37, 1749-1755 (1993).

20) Yasuda H, Ajiki Y, Koga T, Yokota T. Interaction between clarithromycin and biofilms formed by Staphylococcus epidermidis. Antimicrob. Agents Chemother., 38, 138-141 (1994).

21) Ofek I, Hasty DL, Sharon N. Anti-adhesion surfaces. Arch. Microbiol., 75, 374-381 (2003).

22) Sandasi M, Leonard CM, Viljoen AM. The in vitro antibiofilm activity of selected culinary herbs and medicinal plants against Listeria monocytogenes. Lett. Appl. Microbiol., 50, 30-35 (2010).

23) Soumya EA, Saad IK, Hassan L, Ghizlane Z, Hind M, Adnane R. Carvacrol and thymol components inhibiting Pseudomonas aeruginosa adherence and biofilm formation. African J. Microbiol. Res., 5 , 3229-3232 (2011)

24) Packiavathy IASV, Agilandeswari P, Musthafa KS, Pandian SK, Ravi AV. Antibiofilm and quorum sensing inhibitory potential of Cuminum cyminum and its secondary metabolite methyl eugenol against gram negative bacterial pathogens. Food Res. Int., 45, 85-92 (2012). 